\title{
Ergonomia no trabalho dos operadores de caixa de supermercado
}

\author{
Ergonomics at work of supermarket cashiers
}

Ana Paula Silveira da Silva'

Lidiane Bittencourt Barroso²

Nirvan Hofstadler Peixoto ${ }^{3}$

\section{RESUMO}

Os operadores de caixa (checkout) de supermercado ocupam um posto de trabalho que necessita adequações devido aos riscos a que estes estão expostos durante a realização das suas atividades. Com o intuito de analisar quais riscos são estes, foi executada uma análise ergonômica do posto de trabalho dos operadores de checkout em quatro supermercados da cidade de Santana do Livramento-RS. A coleta de dados foi realizada por meio de checklist com fotografias e questionário em forma de entrevista com os operadores. Com o checklist, verificou-se o cumprimento de cada item do anexo I da norma regulamentadora que trata de ergonomia nas dependências de cada supermercado e a entrevista foi utilizada como complemento para verificar a satisfação ou insatisfação dos operadores com seus postos de trabalho e seu trabalho em si. Com este estudo foi possível identificar alguns aspectos sociais dos operadores de caixa, analisar os seus postos de trabalho e verificar o esforço dos operadores da manipulação das mercadorias.

Palavras-chave: Análise ergonômica. Posto de trabalho. Operadores de checkout.

$\begin{array}{ll}1 & \text { Universidade Federal de Santa Maria - Colégio Técnico Industrial | silveiranapa@hotmail.com } \\ 2 & \text { Universidade Federal de Santa Maria - Colégio Técnico Industrial | lidianebarroso@gmail.com } \\ 3 & \text { Universidade Federal de Santa Maria - Colégio Técnico Industrial | nirvan.peixoto@gmail.com }\end{array}$ 


\section{Ergonomia no trabalho dos operadores de caixa de supermercado}

\section{Ergonomics at work of supermarket cashiers}

\section{ABSTRACT}

The supermarket cashiers (checkout) occupy a job that requires adjustments due to the risks to which they are exposed during the performance of their activities. In order to analyze what risks are these, it was performed an ergonomic analysis of the job of checkout operators at four supermarkets in the city of Santana do Livramento - RS. Data collection was carried out through checklist with photos and questionnaire as an interview with operators. With the checklist verified, it compliance of each item of Annex I of the regulation that deals with ergonomics on the premises of each supermarket and the interview was used as a supplement to check the satisfaction or dissatisfaction of operators with their jobs and their work. This study was possible to identify some social aspects of cashiers, analyze their jobs and check the efforts of operators handling the goods.

Keywords: Ergonomic analysis. Job. Checkout operators. 


\section{Introdução}

Entre tantas profissões, os operadores de caixa de supermercado ocupam um posto de trabalho que necessita adequações, devido aos riscos a que estes trabalhadores estão expostos durante a realização das suas atividades, por exemplo, têm sido detectados transtornos do sistema musculoesquelético, dores de cabeça, transtornos do sono e do apetite, transtornos nervosos e fadiga visual (BATIZ et al. 2009). A implantação de um sistema automatizado nas "frentes de lojas" (checkouts) tem-se dado de forma empírica no que diz respeito à ergonomia (PERES et al. 1999).

A ergonomia é o estudo da adaptação entre homem e trabalho. A adaptação ocorre sempre do trabalho para o homem, pois é muito mais difícil adaptar o homem ao trabalho. Isto significa que a ergonomia parte do conhecimento do homem para fazer o projeto do trabalho, ajustando-se às capacidades e limitações humanas (IIDA, 2001). O trabalho, sob a ótica ergonomista, é toda a situação em que ocorre a relação do homem com a atividade produtiva e não só trabalhos com máquinas, braçal ou de escritório (IIDA, 2005).

Conforme o anexo I da Norma Regulamentadora nº17 - Ergonomia (Brasil, 2007) que visa a estabelecer parâmetros e diretrizes mínimas para adequação das condições de trabalho dos operadores de checkout, foi realizada uma Análise Ergonômica do Trabalho (AET) com o objetivo de elucidar se as condições de trabalho oferecidas aos operadores de caixa se adéquam as suas necessidades reais. A análise ergonômica do trabalho é um método que busca conhecer quais tarefas foram realizadas e quais atividades são desenvolvidas para realizá-las.

Além disso, pretende-se avaliar como essa atividade se realiza e quais dificuldades são encontradas pelos operadores de caixa. O presente trabalho foi desenvolvido a partir de dados coletados junto aos operadores de caixa de quatro supermercados da cidade de Santana do Livramento - RS, por intermédio dos quais foi realizado o estudo do posto de trabalho dos mesmos, focando no mobiliário, nos fatores ambientais existentes, na postura e na presença ou ausência de algia (dor).

\section{Metodologia}

Foi realizado um estudo de campo em quatro supermercados de Santana do Livramento - RS, escolhidos devido ao grande fluxo de clientes. Foram entrevistados vinte e um operadores de caixa, sendo que dois ficaram fora do estudo devido ao tempo de trabalho ser menor do que um mês.

Primeiramente, foi aplicado um checklist aos fiscais de caixa para caracterização dos postos de trabalho em estudo. As questões foram aplicadas com o intuito de saber a quantidade total de operadores de caixa, o número de checkouts funcionantes, em quantos turnos estava dividido a jornada e o número de operadores. Foi possível, em dois dos supermercados visitados, a obtenção de registros fotográficos.

A coleta de dados junto aos operadores de caixa foi realizada no período matutino, durante a jornada de trabalho dos mesmos, com base no questionário de sintomas e de aspectos da organização do trabalho de Peres et al. (1999). Foi criado o questionário abordando as questões:

I Idade?

I Sexo?

Escolaridade?

I Tempo de trabalho?

I Quantas horas são trabalhadas diariamente?

I Possui curso de operador(a) de caixa?

I Sente dor, onde?

I Edema de membros inferiores? 
I No final da jornada se sente cansada ou estressada?

I Existem pausas para ir ao banheiro durante a jornada de trabalho?

I Costuma revezar entre as posturas, sentada e em pé?

I A cadeira possui regulagem de altura?

I De quanto tempo é o intervalo?

I A empresa disponibiliza água potável?

I Alguma sugestão para melhorar o ambiente de trabalho?

\section{Resultados e discussão}

Este capítulo trata dos resultados e discussões acerca da caracterização dos três supermercados e hipermercado, dos postos de trabalho dos operadores de caixa (checkout), análise dos movimentos das atividades realizadas pelos operadores de checkout nos supermercados em estudo, aspectos sociais dos dezenove entrevistados.

\subsection{Caracterização dos postos de trabalho em estudo}

Na Classificação Nacional por Atividade Econômica (Brasil, 2011), define-se como supermercado o comércio varejista de mercadorias em geral, com predominância de produtos alimentícios, com área de venda entre 300 e $5.000 \mathrm{~m}^{2}$. Já com área de venda superior a $5.000 \mathrm{~m}^{2}$ define-se como hipermercado.

O estudo de campo esteve presente em três supermercados e um hipermercado, sendo suas características obtidas a partir de um checklist com os fiscais de caixa.

Supermercado A: foram entrevistados três colaboradores. O supermercado possui dez operadores de caixa com nove empacotadores. São dez checkouts em funcionamento. A jornada de trabalho está dividida em quatro turnos, com três operadores entrando às $8 \mathrm{~h}$ e $30 \mathrm{~min}$, mais dois às $9 \mathrm{~h}$, mais dois às $9 \mathrm{~h}$ e 30 min e por fim três operadores às $10 \mathrm{~h}$, totalizando assim a equipe completa de operadores de checkout. Apresenta checkout com bancada em forma de L, não possui esteira rolante, caracterizando-se como semiautomatizado. Não apresenta quinas vivas e não há balança para pesagem nos checkouts.

Supermercado B: foram entrevistados três colaboradores. O supermercado possui quinze operadores de caixa com dez empacotadores. São doze checkouts em funcionamento. A jornada de trabalho está dividia em dois turnos, com oito operadores entrando no turno matutino das $8 \mathrm{~h}$ e $30 \mathrm{~min}$ às $15 \mathrm{~h}$ e $50 \mathrm{~min}$ e sete no turno vespertino das $13 \mathrm{~h}$ às $20 \mathrm{~h}$ e $20 \mathrm{~min}$. Apresenta checkout com bancada em forma de L, possui esteira rolante, caracterizando-se como automatizado. Não apresenta quinas vivas e não há balança para pesagem nos checkouts.

Supermercado C: foram entrevistados sete colaboradores. O supermercado possui quinze operadores de caixa com doze empacotadores. São quinze checkouts em funcionamento. A jornada de trabalho está dividida em cinco turnos, com três operadores entrando às $8 \mathrm{~h}$ e $30 \mathrm{mim}$, mais três às $9 \mathrm{~h}$, mais três às $9 \mathrm{~h}$ e $30 \mathrm{~min}$, mais três às $10 \mathrm{~h}$ e por último mais três às $10 \mathrm{~h}$ e $30 \mathrm{~min}$, sendo esse o último turno. Apresenta checkout com bancada em forma de L, possui esteira rolante, caracterizando-se com automatizado. Não apresenta quinas vivas e há balança para pesagem nos checkouts.

Supermercado D (ou Hipermercado D): foram entrevistados oito colaboradores. O hipermercado possui dezoito operadores de caixa com dezesseis empacotadores. São dezoito checkouts em funcionamento. A jornada de trabalho está dividida em dois turnos, com nove operadores entrando no primeiro horário às $8 \mathrm{~h}$ e $30 \mathrm{~min}$ e mais nove no segundo horário às $13 \mathrm{~h}$. Apresenta checkout com bancada em forma 
de L, possui esteira rolante, caracterizando-se como automatizado. Não apresenta quinas vivas e há balança nos checkouts, destaca-se por ser o único estabelecimento que possui apoio para os pés.

\subsection{Posto de trabalho dos operadores de caixa}

Conhecido como caixa, checkout ou posto de trabalho, é onde os operadores realizam as suas atividades dentro dos supermercados. Nos dias de hoje, a maioria dos checkouts é parecida, o que varia é possuir ou não esteira. A figura 1 mostra checkout automatizado, já na figura, 2 vê-se um checkout semiautomatizado.

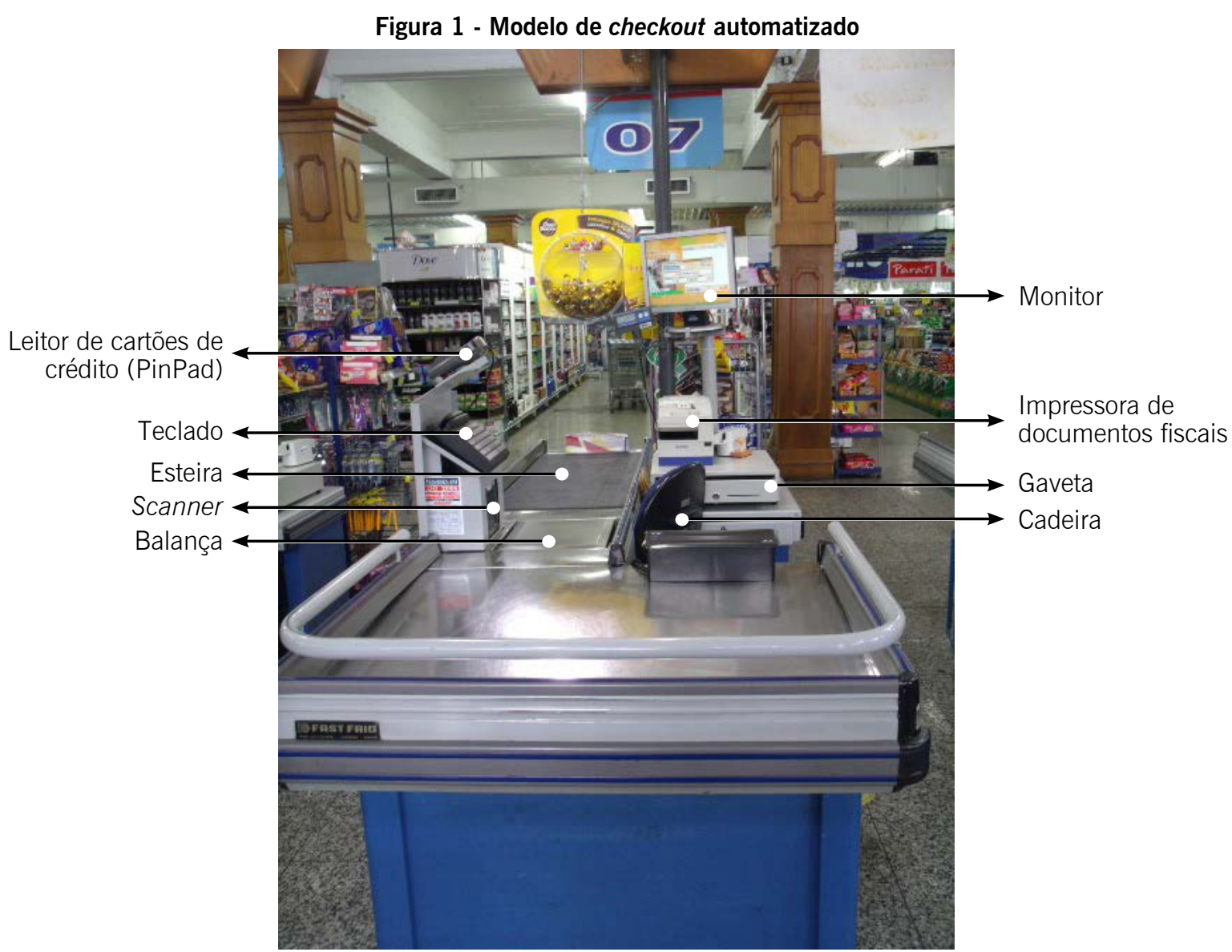

Fonte: Autoria Própria, 2019

Os supermercados atuais possuem checkouts modernos com um balcão/bancada em L (figura 3), onde são colocadas as mercadorias. Esteira elétrica acionada pelo operador, teclado para digitação do preço ou código de barras, balança eletrônica, leitor de cartões de crédito, impressora do cupom fiscal, gaveta para colocação de dinheiro ou cheque, monitor para os clientes visualizarem o preço das mercadorias, caixa ou suporte para sacolas plásticas e cadeira. 


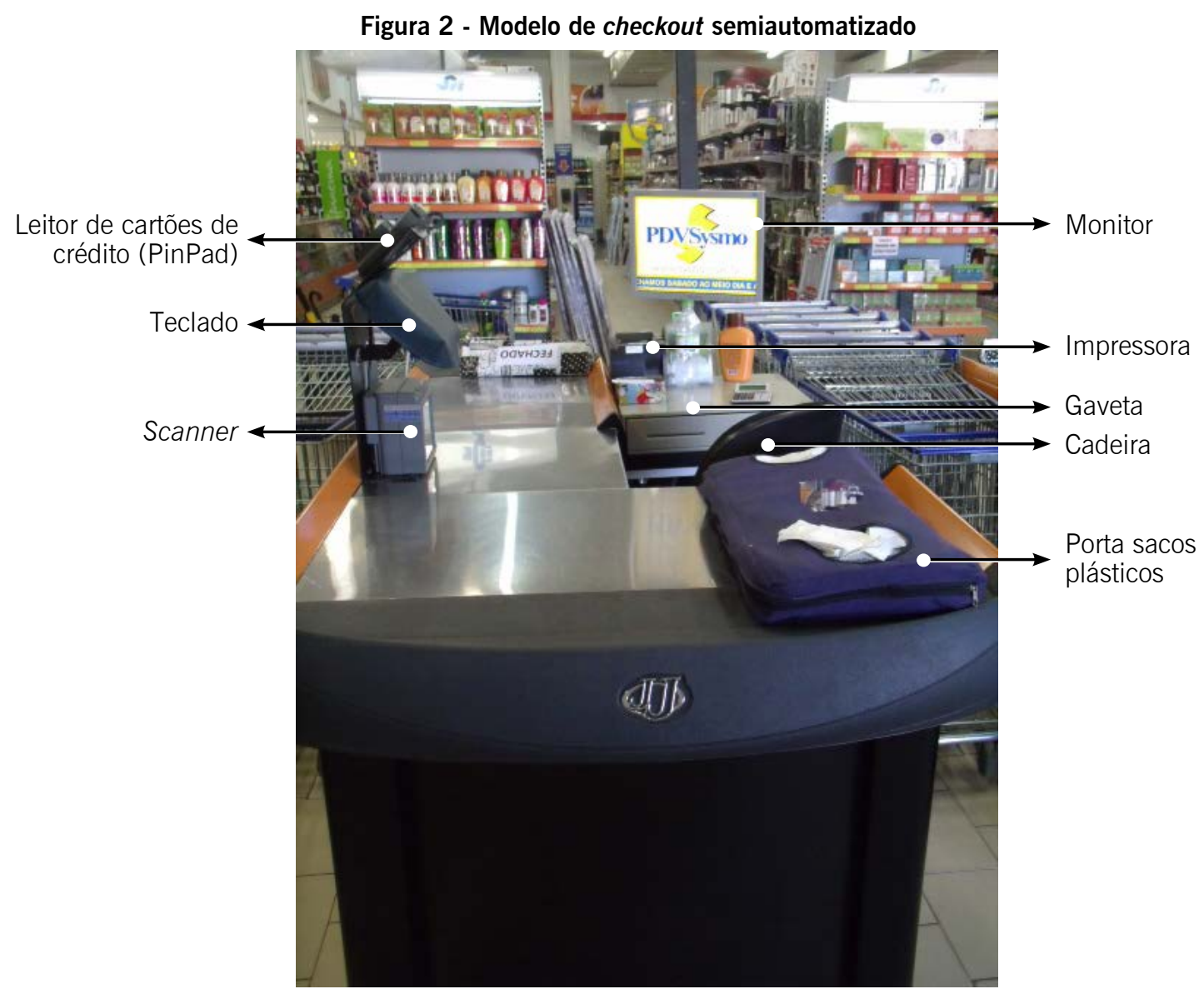

Fonte: Autoria Própria, 2019

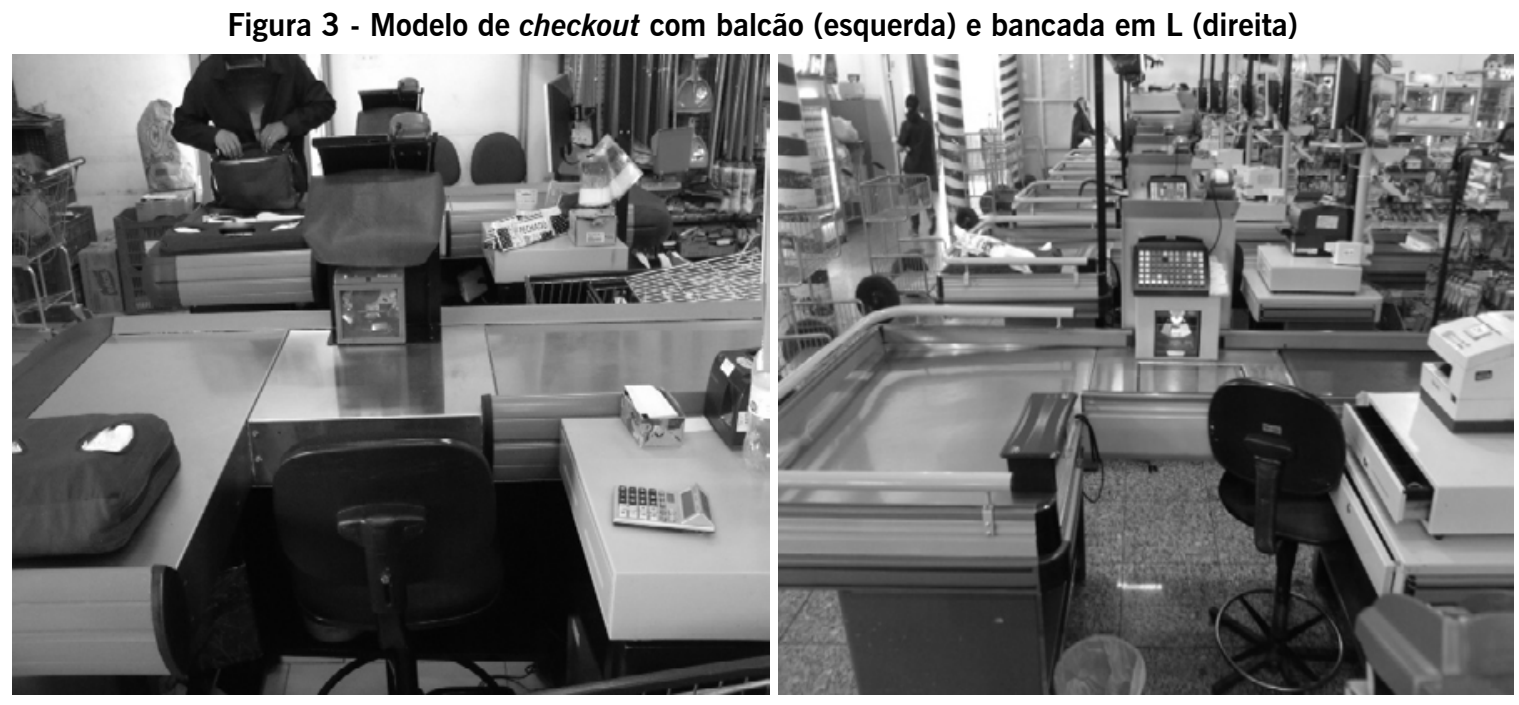

Fonte: Autoria Própria, 2019

Observou-se nos supermercados visitados a não conformidade com o anexo I da NR 17 (Brasil, 2007) subitem 2.3, letra c, que se refere ao uso de superfícies opacas, que evitem reflexos incômodos no campo visual do trabalhador, de acordo com as figuras 1 e 2.

De acordo com a letra e, do subitem 2.1 do anexo I da NR 17 (Brasil, 2007), deve ser mantida uma cadeira de trabalho com assento e encosto para o apoio lombar, com estofamento de densidade adequada, ajustáveis à estatura do trabalhador e à natureza da tarefa, conforme a figura 4. 
Quanto à verificação do esforço dos operadores na manipulação de mercadorias, muitos operadores disseram sentir dores nas costas devido à cadeira ser desconfortável e dificultar o uso do encosto. No tocante à bancada, os maiores esforços são os realizados pelos punhos devido à grande quantidade e peso das mercadorias movimentadas.

Figura 4 - Modelo de cadeiras

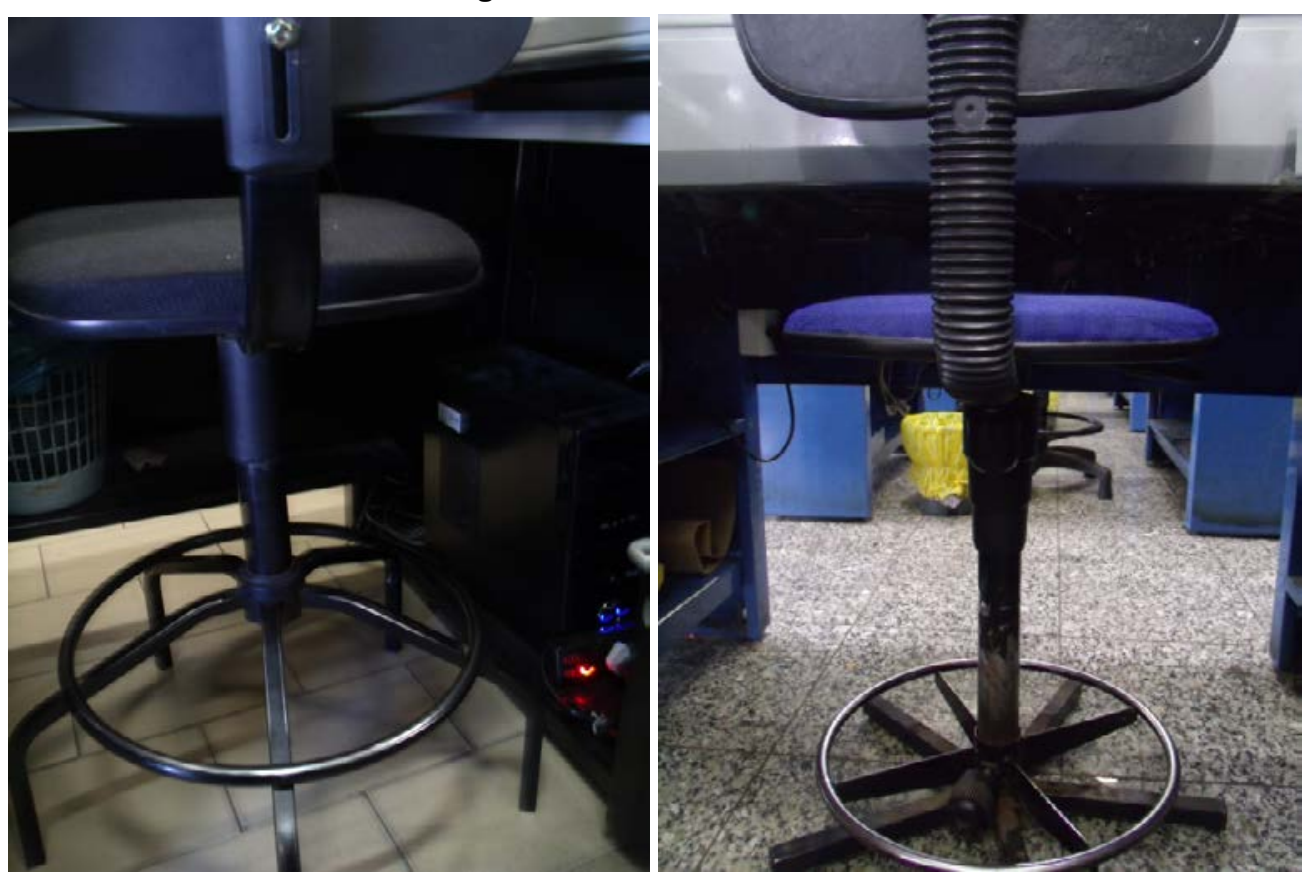

Fonte: Autoria Própria, 2019

Conforme previsto no subitem 1.2 do anexo I da NR 17 (Brasil, 2007) letra f, deve-se colocar apoio para os pés, independentemente da cadeira, o que se verifica não ser utilizado por parte dos operadores nos supermercados entrevistados, de acordo com a figura 5.

Também se observa o descaso com o subitem 2.2 do anexo I da NR 17 (Brasil, 2007) letra c, que visa a garantir a proteção contra acidentes de natureza mecânica ou elétrica nos checkouts, com base no que está previsto nas normas regulamentadoras da Secretaria do Trabalho ou em outras normas nacionais tecnicamente reconhecidas, a probabilidade de acontecer um acidente em ambos os registros fotográficos (figura 6) é grande. 
Figura 5 - Modelo de cadeiras com apoio para os pés inadequados

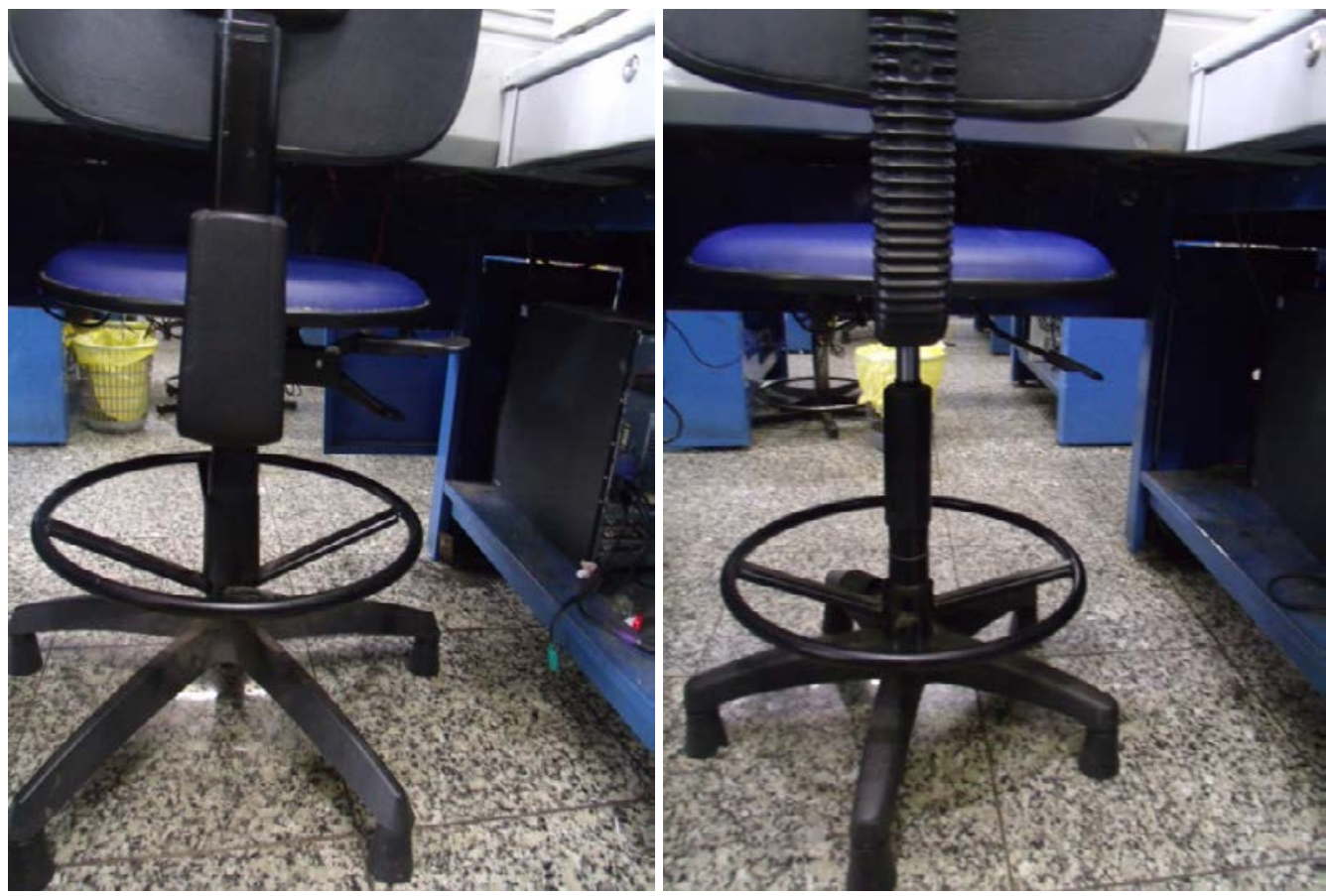

Fonte: Autoria Própria, 2019

Figura 6 - Desorganização da fiação dos checkouts

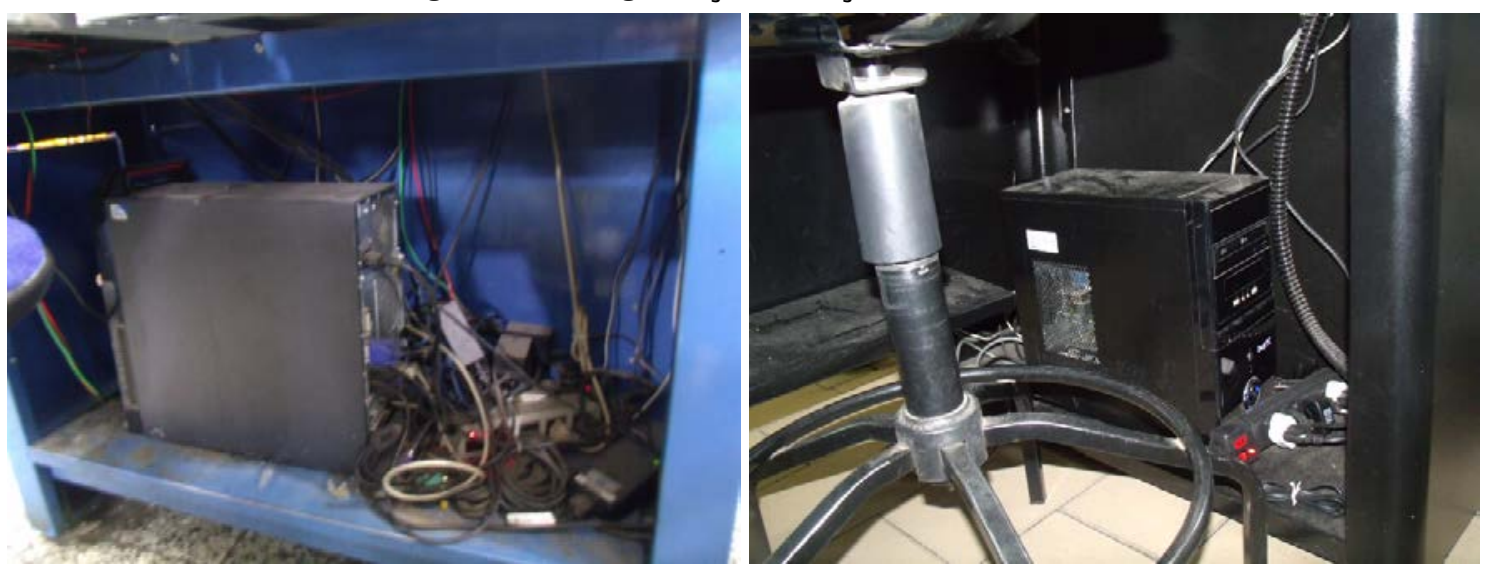

Fonte: Autoria Própria, 2019

\subsection{Análise dos movimentos dos operadores de checkout}

O operador de caixa está à espera do cliente, quando ele enfim chega até o checkout, é cumprimentado pelo operador, enquanto isso o cliente começa a pôr as mercadorias sobre a esteira ou bancada. Caso não possua esteira, o operador vai ter que esticar os braços para trazer as mercadorias até o scanner. Se o checkout possui balança de pesagem, os produtos de hortifrutigranjeiros devem ser pesados e seu código deve ser digitado no teclado, caso contrário somente é necessário passar o código de barras das mercadorias.

Enquanto o operador passa as mercadorias pelo scanner, já disponibiliza para o empacotador, mas se ele não estiver disponível, o próprio operador é quem empacota as mercadorias. Depois das mercadorias empacotadas, informa o valor das compras ao cliente, recebe o dinheiro ou cartão, 
devendo devolver o troco com o cupom fiscal ou o comprovante do cartão, caso necessário, o operador higieniza a esteira.

Em dias de pouco movimento é possível passar boa parte do tempo trabalhando sentado nos checkouts. Nos finais de semana, vésperas de feriado e início de mês a postura considerada melhor é a em pé, devido à grande quantidade de mercadorias que passam pelos checkouts, a movimentação fica mais ágil na postura em pé.

De acordo com Batiz et al. (2009), determinou-se que as atividades realizadas pelos operadores de caixa nos supermercados analisados são:

1. Pegar a mercadoria no início da bancada;

2. Transportar das mercadorias até o leitor óptico;

3. Realizar a leitura óptica;

4. Digitar os números do código de barras, quando não lidas pelo leitor óptico;

5. Conduzir o produto registrado para a extremidade posterior da esteira;

6. Empacotar;

7. Fazer manutenção da ordem e higienização do posto de trabalho;

8. Cobrar;

9. Outras atividades a serem realizadas pelos operadores de caixa: observação para que todos os produtos sejam registrados, troca de produtos à solicitação do cliente, entrega do dinheiro existente no caixa ao fiscal, solicitação de troco de dinheiro com outros caixas ou com o fiscal.

\subsection{Aspectos sociais dos entrevistados}

Com base nas perguntas feitas para os dezenove operadores de caixa, as figuras 7 a 15 mostram as respostas fornecidas pelos entrevistados.

Com relação à idade dos entrevistados, pode-se perceber que a população predominante é jovem. A figura 7 mostra a proporção dos dados analisados, ficando evidente que abrangem quatro faixas etárias.

Figura 7 - Distribuição de idades dos operadores de caixa

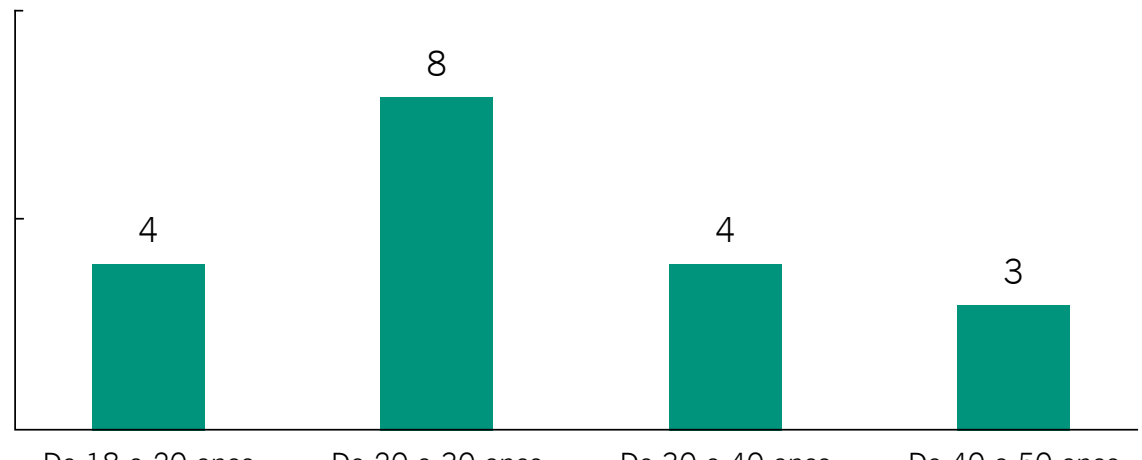

Fonte: Elaborado pelos autores com base nas entrevistas, 2019

Pode-se constatar que a população é predominantemente feminina. No estudo realizado, 94,7\% dos operadores entrevistados são do sexo feminino, sendo $5,3 \%$ do sexo masculino. $E$, com base na figura $8,9,68 \%$ dos entrevistados possui o ensino médio completo, e apenas um tem ensino superior completo. 


\section{Figura 8 - Grau de escolaridade dos operadores de caixa}

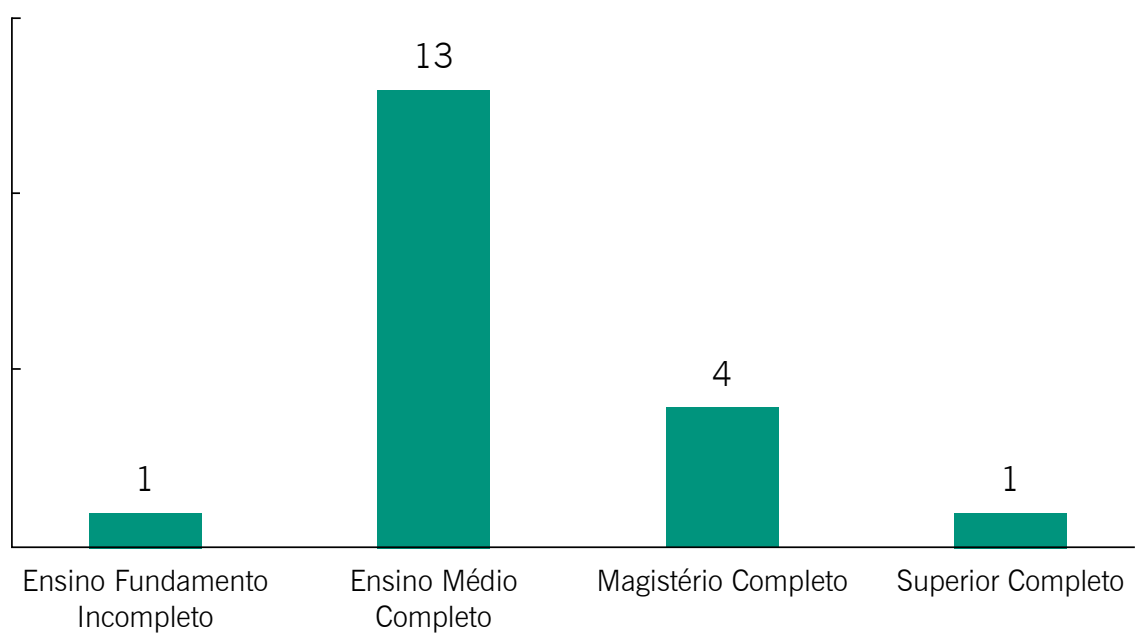

Fonte: Elaborado pelos autores com base nas entrevistas, 2019

Conforme Moreira et al. (2011), o trabalho de operador de checkout é extremamente rotativo. A maioria dos profissionais não fica mais de dois anos na empresa, como visto na figura 9 , a informação se confirma também neste estudo.

Figura 9 - Tempo no cargo dos operadores de caixa

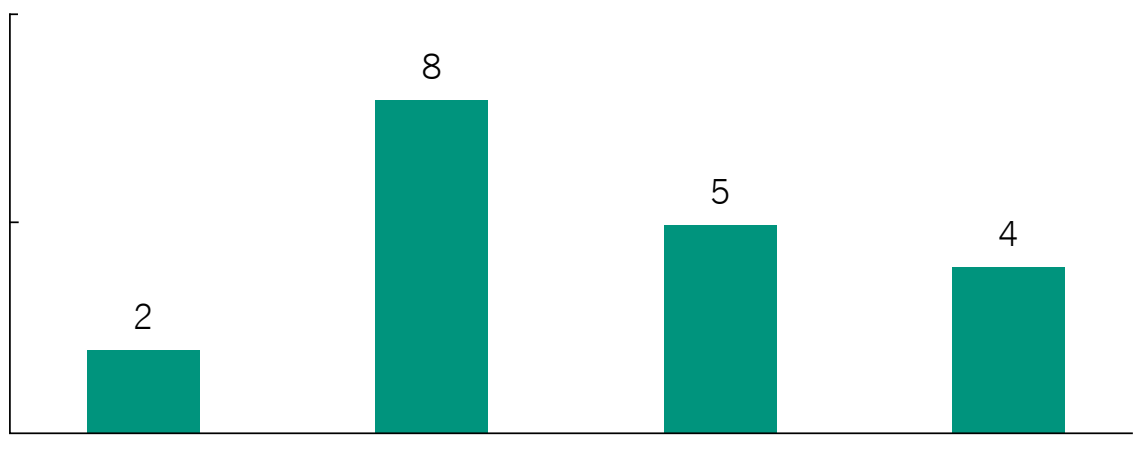

De 2 a 5 meses De 5 meses a 1 ano De 1 a 2 anos De 2 anos a mais

Fonte: Elaborado pelos autores com base nas entrevistas, 2019

Quando questionados sobre o tempo de permanência no posto de trabalho, nos quatro supermercados visitados a informação dada foi de $7 \mathrm{~h}$ e 20 min. Porém, ficar a mais do tempo limite é regra em todas as empresas, afinal enquanto houver clientes eles estarão sendo atendidos.

Para tornar-se operador de caixa, na cidade em estudo não é obrigatório ter curso; quanto maior a qualificação melhor é para o operador de checkout. No estudo em questão, em apenas um dos supermercados visitados os operadores de checkout disseram ter tido treinamento antes de iniciar no cargo, mas nos três outros foi falado que a aprendizagem se dá através do olhar, ou seja, observar um operador experiente realizar suas tarefas diárias. Apenas uma operadora de caixa fez curso por conta própria, o restante aprendeu nos treinamentos que os supermercados costumam oferecer aos novos operadores de caixa ou somente visualizando os outros fazerem.

Com base no estudo de Moreira et al. (2011), em relação ao treinamento, os dois supermercados visitados no Rio de Janeiro oferecem um treinamento cauteloso e atualizado no intervalo de dois em dois anos. Contudo, nos supermercados de Nova Iguaçu os trabalhadores divulgaram que nunca 
tiveram treinamento. A forma de aprendizagem era através da visualização das tarefas feitas por outros operadores, em aproximadamente dois dias de observação.

Quando perguntado se os operadores sentiam alguma dor, onze $(57,89 \%)$ operadoras disseram que sim. Avaliando o questionário fica evidente que o fato de sentir dor ou não está diretamente ligado com o tempo no cargo. Operadores com menos tempo de trabalho não sentem dor ou pelo menos não revelaram sentir, e os que estão por mais tempo sim, dizem ser acometidos por dores em geral.

Com base no estudo de Cabral (2013), após a realização do trabalho pode-se concluir que 91,67\% dos trabalhadores apresentam queixas de dores nas pernas, $83,33 \%$ reclamam de altas temperaturas e 33,33\% de dores no antebraço direito. Contrariando o estudo de Cabral (2013), neste estudo, nenhum operador referiu-se a dores nas pernas e sim por apresentarem edema, oito operadores deram como sugestão de melhora que o ar-condicionado fosse mais eficiente, sendo que quatro disseram apresentar dor nos braços, ombros e punhos.

O edema periférico é o nome que se dá ao inchaço das pernas, pé e tornozelo em decorrência da acumulação de líquidos e uma de suas causas é de ficar muito tempo sentado ou em pé. De acordo com Vézina et al. (1998), o edema nos membros inferiores se dá devido à diminuição da circulação linfática.

Quanto aos edemas nos membros inferiores, de acordo com a figura 10, 47,36\% dos entrevistados disseram apresentar edema nos membros inferiores, este mal acomete as operadoras devido à dificuldade de acomodação dos joelhos, pernas e pés. A compressão da face posterior dos músculos da coxa e da panturrilha, provocada pela inadequação do mobiliário do checkout e a outras características das atividades de trabalho comprometem o conforto circulatório fazendo com que apareça o edema.

Figura 10 - Percentual dos operadores de caixa que apresentam edema nos membros inferiores

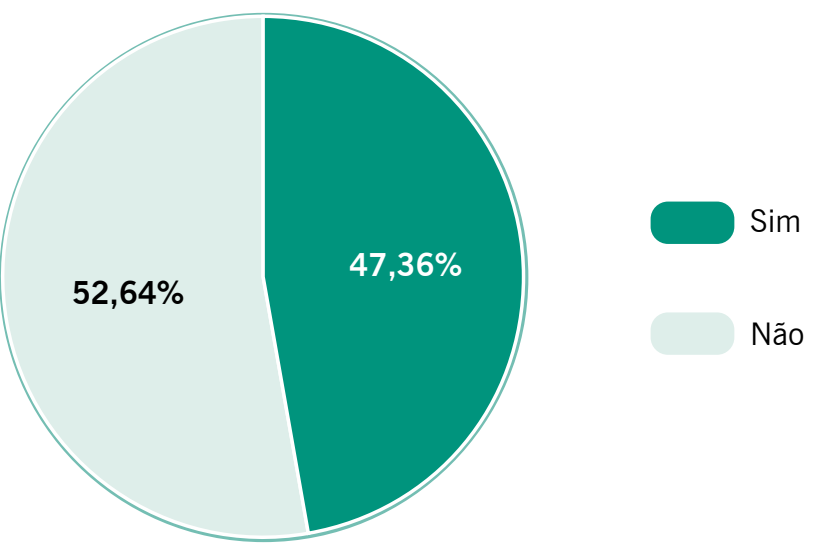

Fonte: Elaborado pelos autores com base nas entrevistas, 2019

O ritmo de trabalho nos supermercados é intenso, filas enormes, clientes também cansados e sem paciência, saber lidar com as adversidades acaba cansando o corpo e a mente dos operadores. No estudo de Junior e Rodrigues (2005), em relação ao estresse no espaço de trabalho, foram obtidos relatos de estresse com maior incidência no supermercado 3, porém em todos os outros mercados houve pelo menos um relato de estresse.

De acordo com o estudo em Santana do Livramento, a maior incidência de estresse ou fadiga se deu no supermercado $C$ com seis operadoras, no supermercado $A$ foram três operadoras, no supermercado B uma operadora e no hipermercado $D$ quatro operadoras disseram se sentir estressadas ou fadigadas após a jornada de trabalho. E, sentir-se estressa ou fadigada após a jornada de trabalho, é quase que rotina. 
Silva e Melo (2001) mencionam que o estresse pode se originar, basicamente, de três fontes: da família, do trabalho e do ambiente em que se vive. De acordo com o estudo em questão, 26,32\% disseram não se sentirem cansados e/ou fadigados após a jornada de trabalho, mas 73,68\% relataram sentirem-se estressados e/ou fadigados (Figura 11).

\section{Figura 11 - Percentual dos operadores de caixa que apresenta estresse ou fadiga no trabalho}

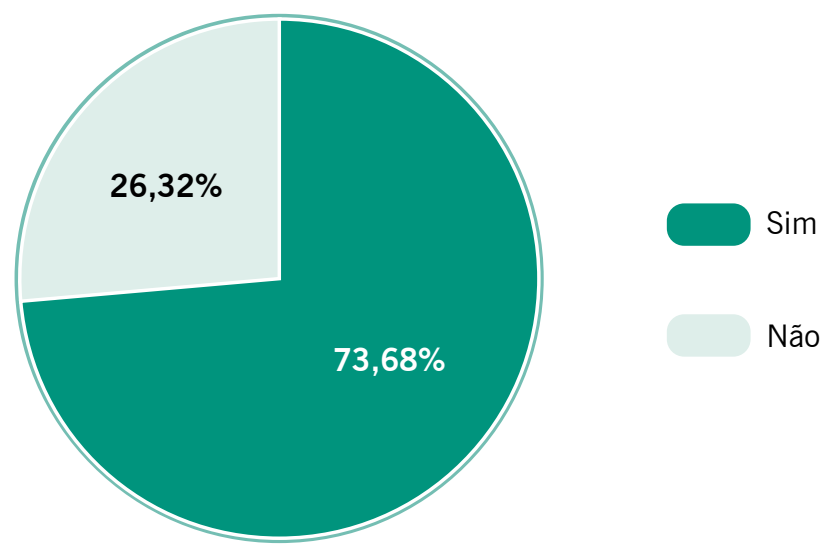

Fonte: Elaborado pelos autores com base nas entrevistas, 2019

Com o aprofundamento deste tema, Batiz et al. (2009) afirmam que a atividade analisada pode ser considerada de risco devido às condições em que é realizada. Pois, é altamente repetitiva, monótona e estressante, composta de uma alta carga física e mental.

Para a pergunta 'Existem pausas para ir ao banheiro durante a jornada de trabalho?', a resposta é sim, mas só após não ter fila e não ao mesmo tempo que outro operador de caixa. Os supermercados em questão não oferecem pausas regulares durante a jornada de trabalho.

\section{Figura 12 - Respostas sobre as pausas para ir ao banheiro durante a jornada de trabalho, dos operadores de caixa}

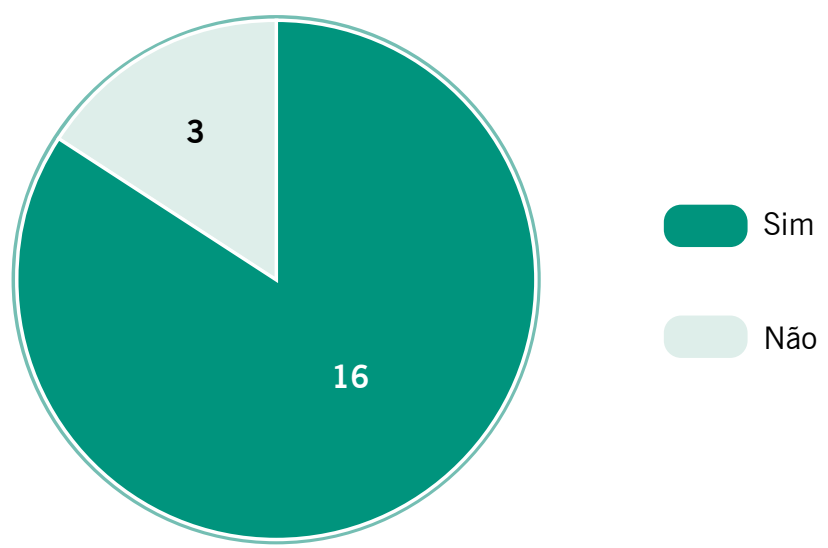

Fonte: Elaborado pelos autores com base nas entrevistas, 2019

Assegurar a postura do trabalho na posição sentada e em pé e as posições confortáveis dos membros superiores e inferiores deve ser objetivo fundamental no design dos postos de trabalho dos operadores de checkout (BRASIL, 2007). Conforme a figura 13, a maioria das entrevistadas respondeu revezar entre a postura sentada e em pé.

De acordo com Vézina et al. (1998), as consequências do trabalho estático em pé são as seguintes: aparecimento de varizes devido à pressão hidrostática nas veias das pernas; desenvolvimento 
de edema nos membros inferiores devido à diminuição da circulação linfática; sintomas de dor nos membros inferiores e na região lombar; sendo que o quadro doloroso nesta região é relacionado com maior risco de ferimentos durante a manutenção de cargas.

Enquanto para Assunção (2004), a postura sentada e imóvel, de acordo com a qualidade do apoio, pode provocar fadiga muscular lombar e compressão da massa muscular das coxas, que gera dores nos membros inferiores. $\mathrm{O}$ ajuste da altura da cadeira pode influenciar o retorno venoso se houver compressão sobre a parte posterior das coxas.

Figura 13 - Resposta quanto ao revezamento Postural, dos operadores de caixa.

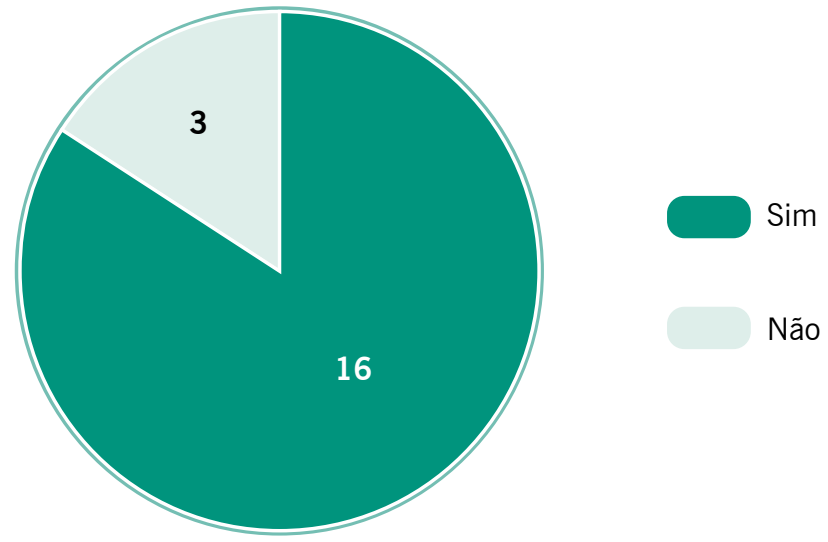

Fonte: Elaborado pelos autores com base nas entrevistas, 2019

Todos os entrevistados disseram que boa parte das cadeiras possuem regulagem de altura. Porém, nem todos operadores regulam a altura no início da jornada de trabalho, pois acreditam que a altura deixada por outro colega no turno anterior esteja adequada para eles.

Quanto ao intervalo de trabalho (figura 14), há diferença de tempo entre os supermercados, variando entre uma hora e cinquenta minutos até três horas, e a maioria dos operadores de caixa faz o intervalo em casa, se não permanecem em uma sala apropriada para o descanso dos funcionários.

Figura 14 - Tempo de intervalo dos operadores de caixa

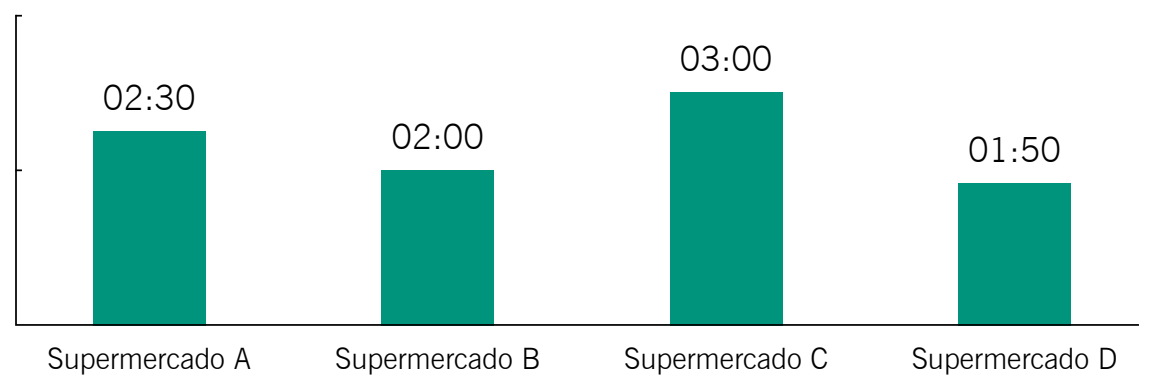

Fonte: Elaborado pelos autores com base nas entrevistas, 2019

Quanto à empresa disponibilizar água potável, todas disseram que sim. No supermercado $\mathrm{A}$, as funcionárias costumam trazer água de casa, mas há próximo aos checkouts um bebedouro com água potável e fresca. No supermercado $B$, as funcionárias costumam trazer água de casa e deixam na geladeira da sala de descanso, no supermercado $C$ foi informado que a água é pega na padaria do supermercado, onde há uma geladeira com água gelada e no hipermercado $D$, existe bebedor próximo aos checkouts onde é possível encher a garrafa com água potável e fresca. 
Alguma sugestão para melhorar o ambiente de trabalho: as sugestões de melhora foram inúmeras, três operadores reclamaram dos horários que ficam a mais, uma operadora do hipermercado D referiu ser regra da empresa que enquanto não houver clientes sendo atendidos no checkout, deve-se ficar em pé na ponta do checkout aguardando, o que é considerado por ela incômodo. Oito operadoras reclamaram que o ar condicionado não era bom, uma operadora disse que o salário é ruim, uma operadora reclamou que as cadeiras são pouco confortáveis e seis operadores disseram não ter sugestões.

\section{Considerações finais}

Neste estudo, foi abordada a análise ergonômica do trabalho com o objetivo de analisar os postos de trabalho em quatro supermercados de Santana do Livramento-RS. Foram cumpridos todos os objetivos propostos, através de visita aos supermercados foi possível identificar os aspectos sociais dos colaboradores, analisar os postos de trabalho (checkouts) e verificar o esforço dos operadores na manipulação de mercadorias.

Os aspectos sociais foram abordados nas perguntas sobre gênero, enfatizando que a maioria dos entrevistados são do sexo feminino. Quanto à idade, a maioria das operadoras é jovem, grande parte delas possui ensino médio completo. Notou-se que é um cargo com grande rotatividade porque a maioria das operadoras não fica por mais de dois anos no cargo.

Quanto ao curso de operador de caixa, não é necessário possuir, mas claro que se está na busca de uma nova vaga de emprego pode ser interessante comentar isso no currículo. Na pergunta sobre as horas de trabalho diárias, todas disseram 7 h e $20 \mathrm{~min}$, mas se vê que os horários dos trabalhadores ultrapassam as horas estabelecidas.

Analisando os postos de trabalho, foi visto que nem todas as cadeiras possuem regulagem de altura, algumas estão estáticas. Assim, alguns dos operadores mais baixos de estatura costumam procurar os checkouts com cadeiras que funcionem quanto à regulagem de altura ou então tem que trabalhar sentindo o desconforto da altura da cadeira durante toda a jornada de trabalho.

A grande maioria das operadoras disse revezar entre as posturas, até porque quando a fila é muito grande parece que na postura em pé o corpo fica mais ágil. O edema de membros inferiores é observado principalmente no verão, quando os operadores são acometidos por esse mal.

Não existem pausas para descanso durante a jornada, o que ajudaria na recuperação da sobrecarga mental e física. Deve-se ir ao banheiro de preferência durante o período de intervalo, durante a jornada de trabalho pode se tornar uma tentativa frustrada.

Pode-se ver que a atividade dos operadores de caixa precisa de uma intervenção urgente, que inclui o design adequado do posto de trabalho e de uma melhoria nas condições ambientais e organizacionais. As posturas e o peso a ser manuseado são responsáveis pelo grande número de trabalhadores com dores em diferentes partes do corpo.

As condições do mobiliário que ainda não são adequadas e não se adaptam às características antropométricas dos trabalhadores; implicando entre outros aspectos negativos, constantes movimentos de rotação e inclinação do pescoço e do corpo desnecessários que aumentam a sobrecarga muscular nessas regiões.

Este estudo foi muito importante para os autores na compreensão do tema, pois é uma atividade que cresce de forma acelerada em todas as regiões do Brasil. E, teve também o intuito de levantar problemas para estudos futuros de melhorias na qualidade e produtividade dos operadores de caixa de supermercados da região. 


\section{Referências}

ASSUNÇÃO, Ada Ávila, A cadeirologia e o mito da postura correta. 2004. Revista Brasileira de Saúde Ocupacional, São Paulo, v. 29, n.110. Disponível em: http://www.scielo.br/scielo.php?script=sci_art text\&pid=s0303-76572004000200006. Acesso em: 05/set/2019.

BRASIL. Secretaria do Trabalho Ministério da Economia. Portaria SIT no 8, de 30 de Março de 2007. Aprova o anexo I da NR 17 - Ergonomia no trabalho dos operadores de checkout. Diário Oficial da República Federativa de Brasil, Brasília, DF, 02 de Abril de 2007. Disponível em: http://trabalho.gov. br/seguranca-e-saude-no-trabalho/normatizacao/normas-regulamentadoras/norma-regulamentadora-n-17-ergonomia Acesso em: 05/set/2019.

BRASIL. Secretaria do Trabalho Ministério da Economia. Portaria SIT n. ${ }^{\circ}$ 14, de 21 de junho de 2007 - Classificação Nacional por Atividade Econômica (CNAE). Norma Regulamentadora, NR 5 Comissão Interna de Prevenção de Acidentes. Disponível em: https://enit.trabalho.gov.br/portal/images/ Arquivos_SST/SST_NR/NR-05.pdf Acesso em 05/set/2019.

BATIZ, Eduardo Concepción, SANTOS, Andréia Fuentes dos; LICEA, Olga Elena Anzardo. A postura no trabalho dos operadores de checkout de supermercados: uma necessidade constante de análise, 2009. Produção v.19, n.1, p.190-201. Disponível em: http://dx.doi.org/10.1590/S010365132009000100012 Acesso em: 05/set/2019.

CABRAL, Felipe Maciel. Análise da demanda ergonômica, medição de iluminância e temperatura em um supermercado. 2013. 72 f. Trabalho de Conclusão de Curso (Especialização) - Universidade Tecnológica Federal do Paraná, Curitiba, 2013.

IIDA, Itiro. Ergonomia: projeto e produção. São Paulo: Edgard Blucher, 2001.

IIDA, Itiro. Ergonomia: projeto e produção. 2.ed. São Paulo: Editora Eduardo Blucher, 2005.

JUNIOR, Abelardo da Silva Melo; RODRIGUES, Celso Luiz Pereira. Avaliações de estresse e dor nos membros superiores em operadores de caixa de supermercados na cidade de João Pessoa: estudo de caso. In: ENEGEP, 15., 2005, Anais [...]. XXV ENEGEP, 2005.

MOREIRA, Evandro José Tavares; BASTOS, Tayzi de Souza; NEPOMUCENO, Vicente. Análise exploratória sobre o posto de trabalho de operadores de checkout de supermercados de Nova Iguaçu e Rio de Janeiro. In: ENCONTRO NACIONAL DE ENGENHARIA DE PRODUÇÃO, 31, 2011, Belo Horizonte, Anais Eletrônicos. ABEPRO, 2011. Disponível em: http://www.abepro.org.br/biblioteca/ enegep2011_tn_sto_138_873_17944.pdf Acesso em: 05/set/2019.

PERES, Claudio Cézar et al. A. Multiprofissionalidade e interinstitucionalidade necessárias em uma ação ergonômica complexa. Brasília: Ministério do Trabalho, 1999.

SILVA, Mônica de Assis Salviano; MELO, Talita Galindo de. Medicina do Trabalho: Sintomas Presentes. Revista Proteção, Novo Hamburgo, Junho. 2001.

VÉZINA, Nicole; LABERGE, M.; \& LAJOIE, A. Debout, assis ou assis - debout? Montreal: Formations CSST - IRSST, UQAM. 1998. 